The FASEB Journal express article 10.1096/fj.03-0395fje. Published online December 19, 2003.

\title{
Overexpression of HSP70 in mouse skeletal muscle protects against muscle damage and age-related muscle dysfunction
}

Anne McArdle, ${ }^{*}$ Wolfgang H. Dillmann, ${ }^{\dagger}$ Ruben Mestril, ${ }^{\ddagger}$ John A. Faulkner, ${ }^{\S}$ and Malcolm J. Jackson*

* Department of Medicine, University of Liverpool, Liverpool L69 3GA, UK; ${ }^{\dagger}$ Department of Medicine, University of California, San Diego, CA; ${ }^{\star}$ Department of Physiology, Loyola University, Chicago, IL; ${ }^{\S}$ Institute of Gerontology, University of Michigan, Ann Arbor, MI

Corresponding author: Anne McArdle, Department of Medicine, University of Liverpool, Liverpool L69 3GA, UK. E-mail: mdcr02@liv.ac.uk

\section{ABSTRACT}

Ageing is associated with skeletal muscle atrophy, a deficit in force generation, an increased susceptibility to contraction-induced injury, and a permanent force deficit following severe injury. Muscles of young mice adapt rapidly following exercise by an increase in the production of heat shock proteins (HSPs), whereas muscles of old mice show a severely diminished response. We hypothesized that overexpression of HSP70 in muscle throughout life would reduce age-related changes in function. The maximum tetanic force of extensor digitorum longus (EDL) muscles of adult and old wild-type (WT) and HSP70 overexpressor transgenic mice was determined. EDL muscles were subjected to damaging lengthening contractions and the ability to generate force was assessed for up to 28 days following the contractions. Overexpression of HSP70 in muscles of old transgenic mice prevented the specific force deficit observed in muscles of old WT mice. The complete recovery of muscles of old HSP70 transgenic mice by 14 days following the contraction protocol was in contrast to the $44 \%$ force deficit, which remained in muscles of old WT mice at 28 days following the protocol. These data indicate that a diminished production of HSP70 in muscles of old mammals has a major effect on age-related functional deficits.

Key words: lengthening contractions $\bullet$ regeneration $\bullet$ maximum tetanic force $\bullet$ transgenic

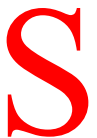

keletal muscle atrophy and weakness are the major causes of the loss in mobility, the high incidence of falls, and the eventual relegation to assisted living conditions and nursing homes for the elderly (1). The cost to society is estimated to be 4 billion dollars per year in the United States alone (2). Muscle atrophy and weakness can arise at any age due to a decrease in habitual physical activity, but under these circumstances the condition is reversible. In contrast, a significant portion of the muscle atrophy and weakness associated with old age is not (3-5). At all ages, skeletal muscles can be injured by contractions, particularly when maximally activated muscles are stretched (6). When maximally activated skeletal muscles of mice are forcibly stretched through single strains of increasing magnitude (7), or with multiple small strains (8), the force deficits and magnitude of the damage for a given strain is almost twofold greater for muscles from old than for those from young or adult mice. Despite this difference in 
susceptibility to injury, a more severe protocol of more than 150 maximum lengthening contractions injured muscles of adult and old mice to the same degree (9). With an injury of this magnitude, the damaged muscles of young/adult mice recover completely within 28 days. In contrast, muscles of old mice do not recover completely (9). Consequently, lengthening contraction-induced injury has the potential to cause permanent deficits in muscle mass and the force developed by muscles of old mice.

Considerable support exits for free radical species having a role in the modulation of the ageing process (10-12). The role of these species in the age-related impairments that occur in skeletal muscles are more complicated than in most other tissues, because skeletal muscles adapt when exposed to conditioning programs. The process of "conditioning" a skeletal muscle is characterized by numerous structural, functional, and biochemical adaptations (13). These adaptations protect the conditioned muscle from subsequent exposures to what had previously been a potentially damaging protocol of contractions (14). Two endogenous protective systems are involved in this adaptation, the antioxidant defense system and stress or heat shock proteins (HSPs; 15). During isometric contractions, skeletal muscles of mice generate superoxide anion radicals $(15,16)$, hydroxyl radicals (17), and nitric oxide (18). This leads to a rapid increase in antioxidant defense enzymes and HSPs (15). Similar adaptations occur in muscles of humans following single leg bicycle ergometry (19).

HSPs are synthesized rapidly in skeletal muscle of a variety of species following a number of different stresses, including high temperatures and repeated contractions $(15,19,20-24)$. We have demonstrated that the production of HSP70 was attenuated in skeletal muscles of old compared with young rats and mice after a nondamaging protocol of 180 isometric contractions $(23,24)$. We conclude that factors influencing the generation of reactive oxygen species, as well as the cellular responses to reactive oxygen species, may play a fundamental role in modulating the ageing processes in muscle. Our aim was to examine the effects of lifelong overexpression of HSP70 in muscles of adult and old transgenic mice in comparison with muscles of adult and old wild-type (WT) mice on the loss of muscle mass, force generation, and susceptibility to damage following a protocol of 450 lengthening contractions, and the ability of muscles to recover from the damage. Our hypothesis was that lifelong overexpression of HSP70 would provide protection against contraction-induced damage and facilitate a rapid and complete recovery following damage, particularly for muscles of old mice.

\section{MATERIALS AND METHODS}

\section{Mice}

The investigation involved adult (10-12 month) and old (26-28 month) male and female WT B6XSJL mice and transgenic mice that had a chimeric transgene that consisted of an inducible HSP70 gene of a rat under a $\beta$-actin promoter (HSP70 transgenic mice; 25). The mice were bred from heterozygous breeding pairs, which produced homozygous, heterozygous, and WT mice. The mice were fed a standard laboratory diet and exposed to a 12-h dark, 12-h light cycle. 


\section{Lengthening contraction protocol}

Experiments were carried out in accordance with UK Government Home Office guidelines. Extensor digitorum longus (EDL) muscles were administered a protocol of 450 lengthening contractions (6). Adult and old mice were anaesthetized with $65 \mathrm{mg} / 100 \mathrm{~g}$ or $40 \mathrm{mg} / 100 \mathrm{~g}$ sodium pentobarbitone respectively by intraperitoneal (i.p.) injection. The depth of the anesthesia was maintained by additional i.p. injections. The knee of the right hind-limb was fixed. The distal tendon was exposed and attached to the lever arm of a servomotor (Cambridge Technology). The lever served as a force and displacement transducer. The peroneal nerve was exposed, and electrodes were placed across the nerve. The EDL muscle of the contralateral limb served as a nonexercized control.

Stimulation voltage and muscle length were each adjusted to produce maximum twitch force. The optimal length for maximum twitch force is also the optimal length $\left(\mathrm{L}_{0}\right)$ for the development of maximum tetanic force $\left(\mathrm{P}_{0} ; 26\right)$. With the muscle at $\mathrm{L}_{0}$, the $\mathrm{P}_{0}$ was determined during 300 msec of voltage stimulation. The $\mathrm{P}_{0}$ was identified by increasing the frequency of stimulation at 2-min intervals until the maximum force plateaued. Muscle fiber length $\left(\mathrm{L}_{\mathrm{f}}\right)$ and cross-sectional area were calculated (26).

Each lengthening contraction began with activation of a muscle at $\mathrm{L}_{0}$ with a stimulation frequency of $150 \mathrm{~Hz}$. The isometric contraction was held for $100 \mathrm{msec}$, and the activated muscle was stretched through a strain of $20 \%$ of $\mathrm{L}_{\mathrm{f}}$ at a velocity of $1.5 \mathrm{~L}_{\mathrm{f}} / \mathrm{s}$. When the stimulation ceased, the muscle was returned to $\mathrm{L}_{0}$. The protocol of 450 lengthening contractions consisted of three 5-min periods with 150 contractions during each period (i.e., one contraction every $2 \mathrm{~s}$ ) and a 5-min rest period between each lengthening contraction period. The protocol was designed to injure EDL muscles of adult and old mice equally (9). After a recovery period of $3 \mathrm{~h}$, the $\mathrm{P}_{0}$ of each muscle was remeasured. A subgroup of mice were killed at this time point, and EDL muscles were removed for analyses described below. The remaining mice in each group were removed from the platform, the incisions were sutured, and mice were allowed to recover. At 3 , 14, and 28 days following the contraction protocol, mice were anaesthetized and $\mathrm{P}_{0}$ was remeasured as described above. The force deficit for each recovery time point was calculated as the difference between a given recovery $\mathrm{P}_{0}$ and the initial $\mathrm{P}_{0}$ for the same muscle, expressed as a percentage of the initial $\mathrm{P}_{0}$.

Following the final measurement, the mouse was removed from the platform. The mouse was weighed, and the EDL muscles were removed immediately. Mice were killed by an overdose of the anesthetic. The muscles were weighed and cut in half through the mid-point. Half of the muscle was mounted on a cork disk, surrounded with mounting medium (O.C.T., Merck, UK), frozen rapidly in isopentane cooled in liquid nitrogen and sectioned for histological analysis. The other half of the muscle was rapidly frozen in liquid nitrogen for analysis of HSP70 content. The specific $\mathrm{P}_{0}$ was calculated as the absolute $\mathrm{P}_{0} /$ total muscle cross-sectional area (27).

\section{Analysis of HSP70 content of muscles by Western blotting}

Muscle samples were homogenized in $100 \mu \mathrm{l}$ of a $1 \%$ solution of sodium dodecyl sulfate (SDS) containing protease inhibitors (15). Each sample was centrifuged at $+4^{\circ} \mathrm{C}$ and the total protein content of the supernatant was measured using bicinchoninic acid (Sigma Chemical, Dorset, 
UK). Total protein was separated by SDS-PAGE using a $12 \%$ polyacrylamide gel (National Diagnostics). Proteins were transferred onto a nitrocellulose membrane by Western blotting as described previously (15). The muscle content of HSP70 was analyzed using a monoclonal antibody (Stressgen, Victoria, Canada). Bands were visualized using an enhanced chemiluminescence (ECL) detection system (Amersham Lifesciences, Amersham, UK) and ChemiDoc image capture system with Quantity 1 software (Bio-Rad, UK).

\section{Histological analysis of EDL muscles}

Transverse sections of muscles $(6 \mu \mathrm{m})$ were stained with hematoxylin and eosin, dehydrated, and mounted in DPX mountant (Merck, UK). Muscles were examined at 3 and 28 days following the lengthening contraction protocol. The University of Texas Health Science Center at San Antonio ImageTool program was used to determine the percentage of the total muscle cross-section composed of intact muscle fibers (compared with areas of nonmuscle and necrotic muscle tissue) was determined in three representative sections from muscles at 3 days following the contraction protocol.

\section{Statistical analysis}

Multiple comparisons were carried out using a one-way ANOVA, with Bonferroni modified $t$ test where appropriate. Individual comparisons were carried out using Student's $t$ test.

\section{RESULTS}

\section{The effect of increased muscle HSP70 content on structure-function relationships in adult and old mice}

No significant differences were observed for the initial $\mathrm{P}_{0}$ or for the force deficits at any of the time points assessed between muscles of heterozygous and homozygous HSP70 mice. Consequently, these data were pooled.

The HSP70 content of EDL muscles of HSP70 heterozygotic and homozygotic mice was increased by $\sim 10-20 \times$ respectively (Fig. $1 A$ ). HSP70 was barely detectable in EDL muscles of WT mice (Fig. 1A). The increased content of HSP70 was maintained in muscle of old HSP70 mice (Fig. 1A). The body masses of WT and HSP70 transgenic mice were smaller than for adult mice of the same strain. The body mass of old WT mice was 13\% less than that of adult WT mice, and the body mass of old HSP70 mice was $16 \%$ less than adult body mass (Table 1). In addition, the body masses of the HSP70 mice were smaller than those of the WT mice: $8 \%$ less for adult mice and $11 \%$ less for old mice (Table 1). The EDL muscle mass of old WT mice was $15 \%$ smaller than that of the adult WT mice. Similarly, muscle mass of old HSP70 mice was $18 \%$ less than that of adult HSP70 mice. The EDL muscle mass of adult HSP70 mice was $17 \%$ smaller than that of the adult WT mice (Table 1). This difference remained in muscle masses of the old mice.

The decrease in absolute $\mathrm{P}_{0}$ of EDL muscles with age was similar in WT and HSP70 mice, with the value for the old WT mice 28\% less than the adult value and 23\% less for the HSP70 mice (Fig. $1 B$ ). No differences were observed between the absolute $\mathrm{P}_{0}$ of EDL muscles of HSP70 and WT mice of the same age. The difference was also reflected in the maximum twitch force values 
(Table 1). The specific $\mathrm{P}_{0}$ for EDL muscles of old WT mice was $26 \%$ less than that of the adult WT mice (Fig. 1C). In contrast, no differences were observed for the specific $\mathrm{P}_{0}$ for the old compared with adult HSP70 mice. No further differences were observed in the twitch characteristics of muscles in any group (Table 1$)$.

\section{Damage to muscles of adult and old WT and HSP70 mice following the lengthening contraction protocol}

At $3 \mathrm{~h}$ following the contraction protocol, the muscles of mice of both adult and old WT and HSP70 transgenic mice had a force deficit of 50-70\%. Between $3 \mathrm{~h}$ and 3 days, the $\mathrm{P}_{0}$ of adult and old WT mice showed a further decrease of $\sim 20 \%$. In contrast, no evidence of a secondary loss of force was observed for muscles of adult or old HSP70 mice at the 3-day time point (Fig. $\underline{2 A}$ ). Three days after the contraction-induced injury, histological analysis of muscles of adult and old age groups of both WT and HSP70 mice showed widespread necrosis with the presence of phagocytic cells within fibers of the EDL muscles (Fig. $2 B$ ). Quantification of the percentage of intact muscle fibers that were present in muscles at 3 days after the contraction protocol demonstrated that a higher percentage of intact fibers remained in muscles of adult HSP70 mice compared with muscles of adult WT mice (Fig. 2C).

\section{Recovery of muscles from adult and old WT and HSP70 mice following a period of lengthening contractions}

The force deficit was eliminated by 28 days after the lengthening contraction protocol in the EDL muscles of adult WT mice. In contrast, the muscles of old WT mice did not recover completely and still demonstrated a force deficit of $44 \%$ at 28 days following the protocol (Fig. $\underline{2 A}$ ). A dramatic improvement occurred in the capacity to develop maximum force in EDL muscles of adult and old HSP70 mice such that no significant force deficit was evident by 14 days following the contraction protocol in either age group (Fig. $2 A$ ). The rapid recovery by the EDL muscles of old HSP70 mice was remarkable when compared with the large and sustained force deficits observed for the old WT mice.

\section{DISCUSSION}

The improved contractility in the HSP70 transgenic mice indicates that the lifelong overexpression of HSP70 in skeletal muscles of the transgenic mice was beneficial. Data have demonstrated that EDL muscles of adult and old HSP70 mice showed a dramatic improvement in the capacity to develop maximum force after a severe lengthening contraction protocol. The rapid recovery by the EDL muscles of old HSP70 mice was remarkable and was in sharp contrast to the persistence of a $44 \%$ force deficit at 28 days for the EDL muscles of old WT mice, a force deficit that is larger than the $20 \%$ force deficit reported for EDL muscles of old WT mice by Brooks and Faulkner (9) that persisted for 60 days. The protection from the more severe secondary injury was evident in the 10-15\% lower force deficits for the muscles of the HSP70 mice at 3 days following the contraction protocol. The number of damaged fibers appeared to be less severe in the muscles of the HSP70 than the WT mice of both ages. In the Brooks and Faulkner study (9), the underlying cause of the force deficit appeared to be a $20 \%$ loss in muscle mass arising from an estimated $20 \%$ loss in the number of fibers. In the current study, although no significant loss in total mass was observed at this time point, a 5-10\% loss in the cross- 
sectional area composed of viable fibers was observed (Fig. $2 B$ ). This was not evident in muscles of adult WT or HSP70 mice. These data indicate that these age-related deficits in skeletal muscle are not inevitable.

The overexpression of HSP70 in the skeletal muscles of transgenic mice reduced body mass by $\sim 10 \%$ and muscle mass by $\sim 20 \%$, compared with the body and muscle masses of adult and old WT mice. Interestingly, the old HSP70 mice were not protected from the age-related muscle atrophy of $\sim 20 \%$ that has previously been observed in WT mice $(26)$, rats $(28,29)$, and humans (3-5). Despite the lower masses and the smaller cross-sectional areas of muscles of the adult HSP70 mice, the absolute $\mathrm{P}_{0}$ of the EDL muscles of the age-matched HSP70 and WT mice were not different. Furthermore, the $\sim 25-30 \%$ age-related loss in absolute $\mathrm{P}_{0}$ of the two strains did not differ significantly from one another or from previous estimates $(26,30)$. In the present study, the deficit in the absolute $\mathrm{P}_{0}$ of $27 \%$ for EDL muscles of old compared with adult WT mice could not be explained by the $8 \%$ loss in total muscle cross-sectional area, resulting in a $25 \%$ decline in specific force. This is in excellent agreement with previous estimates of the deficit attributable to age (26). In contrast to muscles of old WT mice, the specific $\mathrm{P}_{0}$ of EDL muscles of old HSP70 mice was not different from that of the adult HSP70 mice. These data support the hypothesis that overexpression of HSP70 preserve the capability of muscle fibers to generate force per unit cross-sectional area.

The phagocytic infiltration and secondary phase of damage following lengthening contractions are associated with a large increase in production of oxidising free radicals (8). The increased content of HSP70 may provide protection against this increased free radical activity at 3 days following the contraction protocol. Alternatively, HSP70 is a necessary component of the cellular repair machinery. Thus, a proportion of muscle fibers that were reversibly damaged following the contraction protocol may be repaired more readily due to the increased HSP70 content. This suggests that the concentration of this chaperone may be rate limiting in protein synthesis in muscle and is supported by data that have demonstrated that the calcium handling by EDL muscles of these HSP70 mice is more efficient (31).

A decreased capacity for fiber regeneration in muscles of old WT mice agrees with previous reports following contraction-induced injury (9) and whole muscle transplantation $(28,32)$. The impaired regenerative capacity has been associated with the host environment (32). The factors in the environment of the old host are complex and likely vary with the underlying cause of the injury to fibers $(32,33)$. A possible critical issue in the failure of muscle to regenerate in an old host may be the inability of muscle of old rodents to produce HSPs in response to stress. The increased content of HSPs is crucial to structural and biochemical remodeling of muscle, and so the inability to produce HSPs may play a direct role in failure of successful regeneration in muscles of old WT mice. In addition, the phagocytic invasion is prolonged in muscles of old mice following contraction-induced injury, and this prolongation may play an important role in the poor recovery of the muscles. The prolongation may also be related to the inability of muscles of old rodents to produce HSPs. HSPs participate in cytokine signaling and cytokine gene expression and enhance antigen presentation to T lymphocytes (34). Increased HSP content of cells results in an increased resistance to cytokine-mediated toxicity (34). The enhanced regeneration of muscles in transgenic mice may be due to a resistance to cytokine-mediated toxicity and maintenance of efficient antigen presentation. 
In summary, this study is the first to provide direct evidence of a beneficial effect of maintenance of muscle content of HSP70 in old age and is fundamental to our understanding of the consequences of the inability of muscles of old animals to produce these proteins. Data indicate that at least some of the age-related deficits in skeletal muscle are not inevitable and suggest that therapy designed at maintenance of the stress response during normal ageing could impact considerably on the quality of life of the elderly.

\section{ACKNOWLEDGMENTS}

We thank Research into Ageing (grant Q180), the Wellcome Trust (Grant 043364/Z/95/Z), and the National Institutes of Health (WHD, grant R37HL 049434) for funding this study. JAF acknowledges NIA for funding (Ag20591).

\section{REFERENCES}

1. Hadley, E. C., Ory, M. G., Suzman, R., Weindruch, R., and Fried, L. (1993) Physical frailty: a treatable cause of dependance in old age. J. Gerontol. 48, 1-88

2. Lopez, M. E., Zainal, T. A., Chung, S. S., Aiken, J. M., and Weindruch, R. (2000) Oxidative stress and the pathogenesis of sarcopenia. In Handbook of Oxidants and Antioxidants in Exercise (Sen, C. K., Packer, L., and Hanninen, O., eds). Elsevier, Oxford, UK.

3. Lexell, J., Taylor, C. C., and Sjostrom, M. (1988) What is the cause of the ageing atrophy? Total number, size and proportion of different fiber types studied in whole vastus lateralis muscle from 15- to 83-year-old men. J. Neurol. Sci. 84, 275-294

4. Porter, M. M., Vandervoort, A. A., and Lexell, J. (1995) Aging of human muscle: structure, function and adaptability. Scand. J. Med. Sci. Sports 5, 129-142

5. Skelton, D. A., Greig, C. A., Davies, J. M., and Young, A. (1994) Strength, power and related functional ability of healthy people aged 65-89 years. Age Ageing 23, 371-377

6. McCully, K. K., and Faulkner, J. A. (1985) Injury to skeletal muscle fibers of mice following lengthening contractions. J. Appl. Physiol. 59, 119-126

7. Brooks, S. V., and Faulkner, J. A. (1996) The magnitude of the initial injury induced by stretches of maximally activated muscle fibres of mice and rats increases in old age. $J$. Physiol. 497, 573-580

8. Zerba, E., Komorowski, T. E., and Faulkner, J. A. (1990) Free radical injury to skeletal muscles of young, adult, and old mice. Am. J. Physiol. 258, C429-C435

9. Brooks, S. V., and Faulkner, J. A. (1990) Contraction-induced injury: recovery of skeletal muscles in young and old mice. Am. J. Physiol. 258, C436-C442

10. Sohal, R. S., and Orr, W. C. (1992) Relationship between antioxidants, prooxidants, and the aging process. Ann. N. Y. Acad. Sci. 663, 74-84 
11. Warner, H. R. (1994) Superoxide dismutase, aging, and degenerative disease. Free Radic. Biol. Med. 17, 249-258

12. Beckman, K. B., and Ames, B. N. (1998) The free radical theory of aging matures. Physiol. Rev. 78, $547-581$

13. Goldspink, G. (1994) Cellular and molecular aspects of adaptation in skeletal muscle. In Strength and Power in Sport (Komi, P. V., ed) pp. 211-229, Blackwell Science, Oxford, UK

14. Brooks, S. V., Opiteck, J. A., and Faulkner, J. A. (2001) Conditioning of skeletal muscles in adult and old mice for protection from contraction-induced injury. J. Gerontol. A Biol. Sci. Med. Sci. 56, B163-B171

15. McArdle, A., Pattwell, D., Vasilaki, A., Griffiths, R. D., and Jackson, M. J. (2001) Contractile activity-induced oxidative stress: cellular origin and adaptive responses. $\mathrm{Am} . \mathrm{J}$. Physiol. Cell Physiol. 280, C621-C627

16. Reid, M. B., Shoji, T., Moody, M. R., and Entman, M. L. (1992) Reactive oxygen in skeletal muscle. II. Extracellular release of free radicals. J. Appl. Physiol. 73, 1805-1809

17. O'Neill, C. A., Stebbins, C. L., Bonigut, S., Halliwell, B., and Longhurst, J. C. (1996) Production of hydroxyl radicals in contracting skeletal muscle of cats. J. Appl. Physiol. 81, $1197-1206$

18. Balon, T. W., and Nadler, J. L. (1994) Nitric oxide release is present from incubated skeletal muscle preparations. J. Appl. Physiol. 77, 2519-2521

19. Khassaf, M., Child, R. B., McArdle, A., Brodie, D. A., Esanu, C., and Jackson, M. J. (2001) Time course of responses of human skeletal muscle to oxidative stress induced by nondamaging exercise. J. Appl. Physiol. 90, 1031-1035

20. Salo, D. C., Donovan, C. M., and Davies, K. J. (1991) HSP70 and other possible heat shock or oxidative stress proteins are induced in skeletal muscle, heart, and liver during exercise. Free Radic. Biol. Med. 11, 239-246

21. Flanagan, S. W., Ryan, A. J., Gisolfi, C. V., and Moseley, P. L. (1995) Tissue-specific HSP70 response in animals undergoing heat stress. Am. J. Physiol. 268, R28-R32

22. Manzerra, P., Rush, S. J., and Brown, I. R. (1997) Tissue-specific differences in heat shock protein hsc70 and hsp70 in the control and hyperthermic rabbit. J. Cell. Physiol. 170, 130137

23. Vasilaki, A., Jackson, M. J., and McArdle, A. (2002) Attenuated HSP70 response in skeletal muscle of aged rats following contractile activity. Muscle Nerve 25, 902-905

24. Vasilaki, A., Iwanejko, L. M., McArdle, F., Broome, C. S., Jackson, M. J., and McArdle, A. (2003) Skeletal muscles of aged male mice fail to adapt following contractile activity. Biochemical Society Transactions 31, 455-456. 
25. Marber, M. S., Mestril, R., Chi, S. H., Sayen, M. R., Yellon, D. M., and Dillmann, W. H. (1995) Overexpression of the rat inducible 70-kD heat stress protein in a transgenic mouse increases the resistance of the heart to ischemic injury. J. Clin. Invest. 95, 1446-1456

26. Brooks, S. V., and Faulkner, J. A. (1988) Contractile properties of skeletal muscles from young, adult and aged mice. J. Physiol. 404, 71-82

27. Brooks, S. V., and Faulkner, J. A. (2001) Severity of contraction-induced injury is affected by velocity only during stretches of large strain. J. Appl. Physiol. 91, 661-666

28. Carlson, B. M., and Faulkner, J. A. (1988) Reinnervation of long-term denervated rat muscle freely grafted into an innervated limb. Exp. Neurol. 102, 50-56

29. Cederna, P. S., Asato, H., Gu, X., van der Meulen, J., Kuzon, W. M., Jr., Carlson, B. M., and Faulkner, J. A. (2001) Motor unit properties of nerve-intact extensor digitorum longus muscle grafts in young and old rats. J. Gerontol. A Biol. Sci. Med. Sci. 56, B254-B258

30. Phillips, S. K., Bruce, S. A., and Woledge, R. C. (1991) In mice, the muscle weakness due to age is absent during stretching. J. Physiol. 437, 63-70

31. Nosek, T. M., Brotto, M. A., Essig, D. A., Mestril, R., Conover, R. C., Dillmann, W. H., and Kolbeck, R. C. (2000) Functional properties of skeletal muscle from transgenic animals with upregulated heat shock protein 70. Physiol. Genomics 4, 25-33

32. Carlson, B. M., and Faulkner, J. A. (1989) Muscle transplantation between young and old rats: age of host determines recovery. Am. J. Physiol. 256, C1262-C1266

33. Carlson, B. M., Dedkov, E. I., Borisov, A. B., and Faulkner, J. A. (2001) Skeletal muscle regeneration in very old rats. J. Gerontol. A Biol. Sci. Med. Sci. 56, B224-B233

34. Moseley, P. L. (1998) Heat shock proteins and the inflammatory response. Ann. N. Y. Acad. Sci. 856, 206-213 
Table 1

Contractile characteristics of muscles of adult and old WT and adult and old HSP70 transgenic mice ${ }^{\mathrm{a}}$

\begin{tabular}{|l|l|l|l|l|}
\hline \multicolumn{2}{|l|}{ WT mice } & \multicolumn{2}{l|}{ HSP70 transgenic mice } \\
\hline & Adult & Old & Adult & Old \\
\hline Body mass(g) & $30.5 \pm 1.1$ & $26.5 \pm 1.8$ & $28.0 \pm 0.7^{b}$ & $23.6 \pm 1.7^{b, c, d}$ \\
\hline $\begin{array}{l}\text { Muscle mass } \\
(\mathbf{m g})\end{array}$ & $11.6 \pm 0.4$ & $9.9 \pm 0.6^{b}$ & $9.6 \pm 0.4^{b}$ & $7.9 \pm 0.6^{b, c, d}$ \\
\hline $\begin{array}{l}\text { Muscle } \\
\text { mass/body } \\
\text { mass }\end{array}$ & $0.39 \pm 0.01$ & $0.32 \pm 0.03^{b}$ & $0.34 \pm 0.01^{b}$ & $0.30 \pm 0.02$ \\
\hline CSA (mm $\left.{ }^{2}\right)$ & $2.21 \pm 0.09$ & $2.04 \pm 0.80$ & $1.85 \pm 0.09^{b}$ & $1.62 \pm 0.12^{b, d}$ \\
\hline $\mathbf{P}_{\mathbf{t w}}(\mathbf{m N})$ & $161.7 \pm 13.4$ & $127.7 \pm 7.8^{b}$ & $158.3 \pm 10.2$ & $110.8 \pm 7.5^{b, c}$ \\
\hline $\begin{array}{l}\mathbf{P}_{\mathbf{t w}} \\
\left(\mathbf{m N} / \mathbf{m m}^{2}\right)\end{array}$ & $74.4 \pm 11.0$ & $61.4 \pm 4.4$ & $65.6 \pm 4.1$ & $69.7 \pm 4.1$ \\
\hline $\mathbf{T}_{\mathbf{p t w}}(\mathbf{m s e c})$ & $12.8 \pm 0.4$ & $13.0 \pm 0.4$ & $12.5 \pm 0.7$ & $12.7 \pm 0.4$ \\
\hline $\mathbf{T}_{\mathbf{1} / \mathbf{2}}(\mathbf{m s e c})$ & $11.6 \pm 1.1$ & $12.0 \pm 0.8$ & $11.3 \pm 0.6$ & $11.5 \pm 0.7$ \\
\hline
\end{tabular}

${ }^{a} \mathrm{CSA}$, cross-sectional area; $\mathrm{P}_{\mathrm{tw}}$, peak twitch force; $\mathrm{T}_{\mathrm{ptw}}$, time taken to reach peak twitch force; $\mathrm{T}_{1 / 2}$, half relaxation rate.

${ }^{b} P<0.05$, compare with muscles of adult WT mice.

${ }^{c} P<0.05$, compare with muscles of adult HSP70 transgenic mice.

${ }^{d} P<0.05$, compare with muscles of old WT mice. 
Fig. 1

A

$\begin{array}{llllllllllllllllll}1 & 2 & 3 & 4 & 5 & 6 & 7 & 8 & 9 & 10 & 11 & 12 & 13 & 14 & 15 & 16 & 17 & 18\end{array}$

HSP70

B

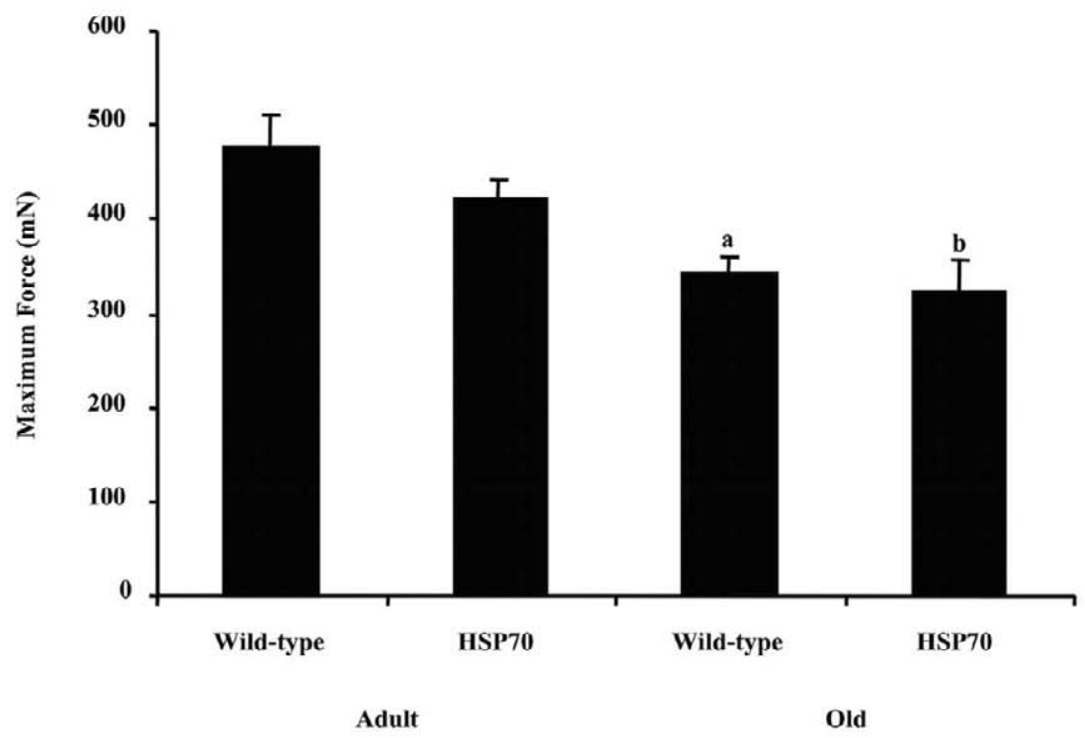

C

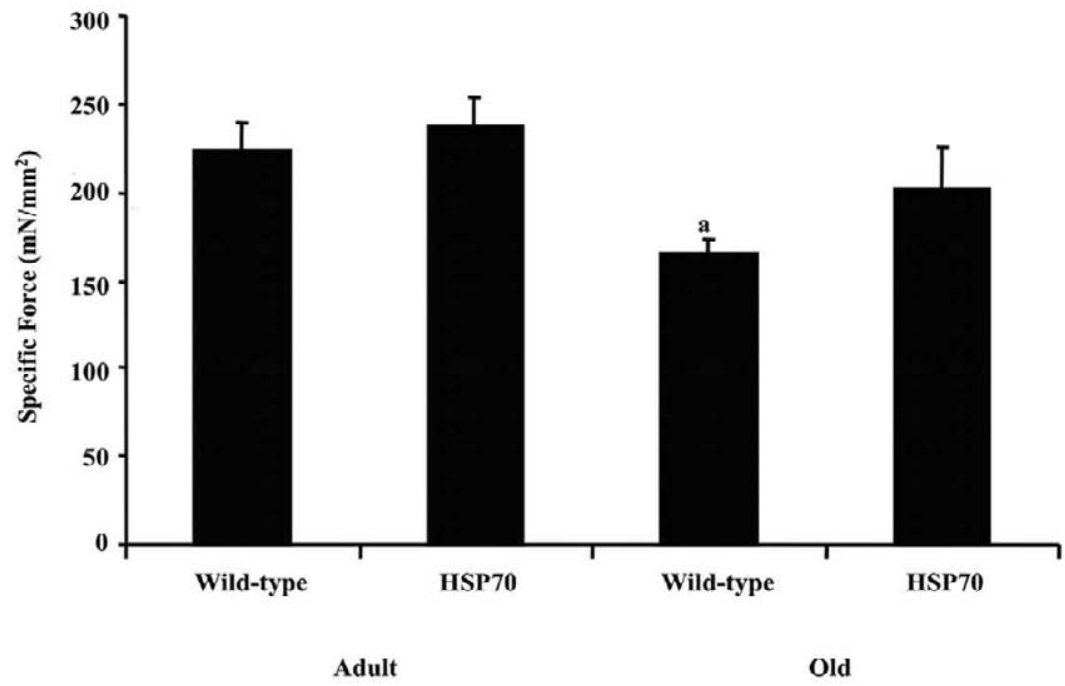

Figure 1. A) Western blot showing HSP70 content of EDL muscles from adult and old wild-type (WT) and HSP70 transgenic mice. (Total protein load $[\mu \mathrm{g}]$ given in parentheses.) Lanes 1-3: adult WT (100 $\mu \mathrm{g})$; lane 4: adult WT (200 $\mu \mathrm{g}$; same sample as lane 3); lane 5: adult heterozygotic HSP70 (100 $\mu \mathrm{g})$; lanes 6 and 8: adult heterozygotic HSP70 (50 $\mu \mathrm{g}$; lane

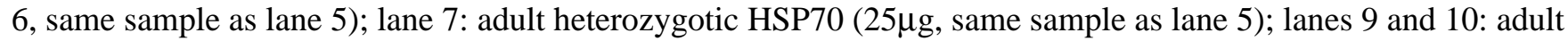
homozygotic HSP70 (50 $\mu \mathrm{g})$; lane 11: adult homozygotic HSP70 (25 $\mu \mathrm{g}$; same sample as lane 10); lanes 12 and 13: old WT $(100 \mu \mathrm{g})$; lane 14: old WT (200 $\mu \mathrm{g}$, same sample as lane 13); lanes 15-17: old homozygotic HSP70 (50 $\mu \mathrm{g})$; and lane 18: old homozygotic HSP70 ( $25 \mu \mathrm{g}$; same sample as lane 17). B) Maximum force generated by EDL muscles of adult and old WT and adult and old HSP70 transgenic mice. ${ }^{\mathrm{a}} P<0.05$, compare with muscles of adult WT mice; ${ }^{\mathrm{b}} P<0.05$, compare with muscles of adult HSP70 transgenic mice. $C$ ) Specific force of EDL muscles of adult and old WT and adult and old HSP70 transgenic mice. ${ }^{\mathrm{a}} \mathrm{P}<0.05$, compare with value for adult WT mice. 
Fig. 2

A

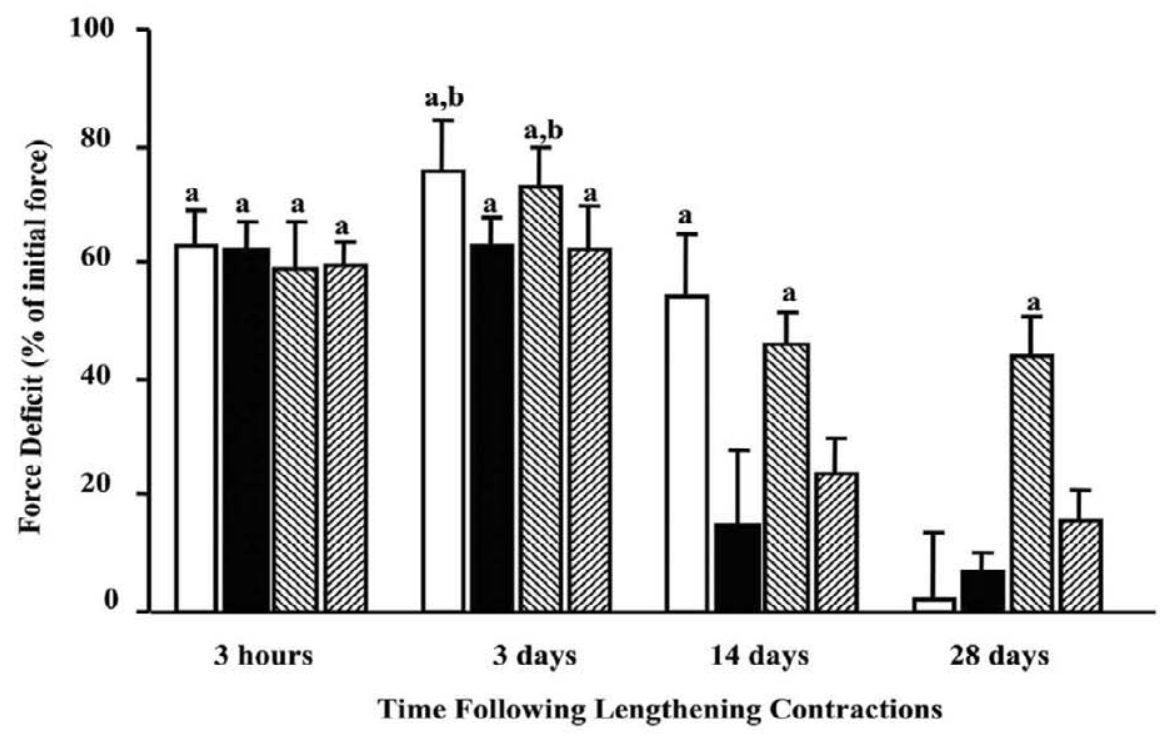

B
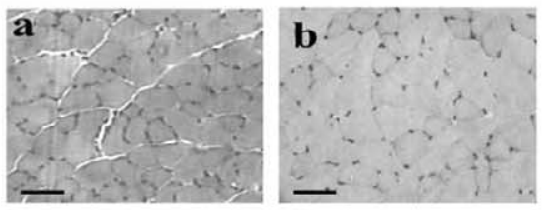

\section{C}
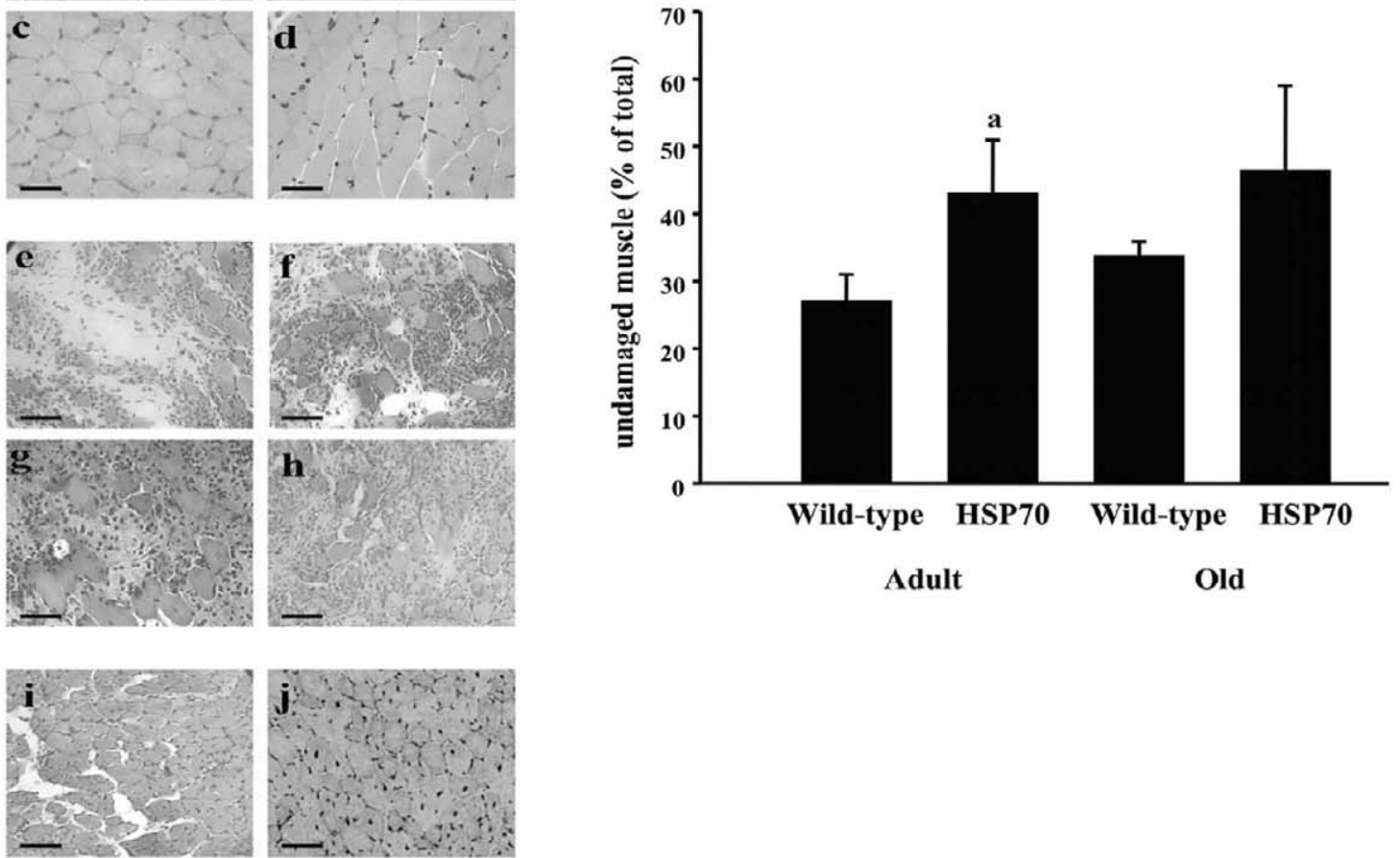

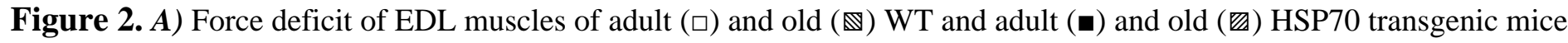
at various time points following the lengthening contraction protocol. ${ }^{\mathrm{a}} P<0.05$, compare with pre-exercise value; ${ }^{\mathrm{b}} P<$ 0.05, compare with data for the same group at the 3-h time point. B) Transverse sections of control muscles from adult WT (a), adult HSP70 transgenic (b), old WT (c), and old HSP70 transgenic (d) mice; from muscles of adult WT (e), adult HSP70 transgenic (f), old WT (g), and old HSP70 (h) mice at 3 days following the contraction protocol; and from old WT (i) and old HSP70 transgenic (j) mice at 28 days following the contraction protocol. Bar, $50 \mu \mathrm{m}$. $C$ ) Percentage of intact fibers remaining in muscles of adult and old WT and HSP70 transgenic mice at 3 days following the contraction protocol. ${ }^{\mathrm{a}} P<0.05$, compare with muscles of adult WT mice. 